\title{
INVESTIGATION OF MECHANICAL PROPERTIES OF CHITOSAN BASED FILMS PREPARED FROM NARMADA RIVERSIDE CRAB SHELLS
}

\author{
Dr. K. K. Gadgey \\ Head, Department of Mechanical Engineering, \\ Government Polytechnic College, Sanawad, Madhya Pradesh, India \\ Dr. G. S. Sharma \\ Professor and Head, Department of Mechanical Engineering, \\ Oriental University, Indore, Madhya Pradesh, India
}

\begin{abstract}
The aim of this investigation is to enhance the utilization of crab waste and help to minimize the environmental pollution. The Narmada riverside crab shells were collected and Chitosan based films prepared. The tensile tests were performed to investigate tensile strength and elongation at break. The tensile strength of pure chitosan films was found to be $122.6 \mathrm{MPa}$ and the elongation at break $13.6 \%$ with film thickness $0.110 \mathrm{~mm}$. The films were plasticized with different percentage of glycerol and the values of film thickness, elongation at break and tensile strength were analyzed. The tensile strength decreased with the increase in glycerol. Film thickness and elongation at break increased with increase in glycerol. The tensile strength of prepared films showed better results compared to previous results of chitosan based films prepared from other sources.
\end{abstract}

Keywords: Biopolymer, Chitin, chitosan, Crab shell, Narmada Riverside

Cite this Article: K.K. Gadgey and G.S. Sharma, Investigation of Mechanical Properties of Chitosan Based Films Prepared from Narmada Riverside Crab Shells. International Journal of Mechanical Engineering and Technology. 11(6), 2020, pp. 21-28.

https://iaeme.com/Home/issue/IJMET?Volume $=11 \&$ Issue $=6$

\section{INTRODUCTION}

The food processing industries produce many by-products. The treatment of the waste produced can help in saving the environment. This waste can turn into useful and valuable products. The crab shells contain chitin, polysaccharides that can be extracted by chemical and biological processes. This biopolymer and its derivative chitosan have many useful applications. Compared to polymeric resources from petroleum, natural polymers from 
renewable resources have the advantages of biodegradability, biocompatibility, non-toxicity, high reactivity, low cost and ease of availability. Narmada riverside crabs are not known to researchers. The quality and quantity of Narmada riverside crab shells or crab waste is not recognized till date. There is no recognized crab industry in India like other countries of the world. Green Technology is a pretty new concept in respect to the environment protection timeline. It is all about the best ways and methods that preserve our natural resources and sustainability of life on our planet earth. It is important to bring technological change for promoting green growth with reduced cost [1]. Biopolymers are polymers produced by living organisms. Bio based plastics and biopolymers have been widely studied in recent years. Replacing the oil-based packaging materials with bio based films and containers might give not only a competitive advantage due to more sustainable and greener image, but also some improved technical properties [2]. Chitin is the second most abundant natural polymer in nature after cellulose [3]. Chitin and its derivatives chitosan have several applications, these include, biomedical, food, emulsifying agent, wastewater treatment, biocatalysts, textile and paper industry and agriculture [4]. It is found in exoskeleton of crustaceans. Crab shell is the most common natural composite material in the world, and one of the most versatile. Very few mechanical studies have been made on the hard shells (solid cuticle) characteristic of the arthropod integument and it is therefore not yet possible to provide a general model for the mechanical behavior of the exoskeletons of this phylum. The exoskeleton of arthropods consists mainly of chitin. In the case of crustaceans, there is a high degree of mineralization, typically calcium carbonate, which gives mechanical rigidity. The various studies have been carried out on insect solid cuticle [5-9] and prawn shells [10]. The arthropod exoskeleton is multifunctional: it supports the body, resists mechanical loads, and provides environmental protection and resistance to desiccation [11-15]. Chitin is a substance that makes up the exoskeleton of insects and crustaceans, which can also be obtained from other sources like fungi, mushrooms, worms, diatoms, etc[16-19]. Chitin and its derivatives chitosan have several applications, these include, biomedical, food, emulsifying agent, waste Chitosan is a natural polysaccharide derived from chitin. The low solubility of chitin derived chitosan in neutral and alkaline solution limits its application. Therefore, the chemical modification into composites and blends brings it into new important functional properties for different engineering applications. It is recognized as versatile biomaterials because of its non-toxicity and biocompatibility. These waste crab shells can be utilized to prepare chitin and chitosan. The extraction of chitin can be done by chemical and biological methods. The crab shell contains chitin, protein and minerals. The deproteinization and demineralization are the main processes to extract chitin from crab shells. The deacetylation of chitin is done to prepare the chitosan which is the important biopolymer to be used mostly in biomedical applications. The chitosan has good film forming capability hence it can replace the polythene bags from the market. It is necessary to know the mechanical strength of the prepared biopolymer. The chitin so produced can be utilized in many applications but there is one important limitation in its utilization, the mechanical strength of the chitin and chitosan is very low. The chitosan films can be prepared to investigate the mechanical properties. Mostly tensile strength and percentage elongation is measured to investigate the mechanical strength of the material. The mechanical strength of the biopolymer can be increased by preparing chitosan composites and blends. A recent study is reported on extraction methods of chitin from crab shell and investigation of its mechanical properties [20]. The present paper describes the preparation of chitin from Narmada riverside crab shells and investigation of mechanical properties of chitosan based films. 


\section{MATERIALS AND METHODS}

\subsection{Preparation of Chitin and Chitosan}

The raw material used in present work was Narmada River Side Crab Shell collected from the fish markets of Nimad region of Khargone, MP, India. Crab shells were cleaned and washed thoroughly to remove any foreign materials, followed by grinding to get particle size 0.30 $0.35 \mathrm{~mm}$. The crab shell were collected and processed to extract chitin and chitosan. Grinding, demineralization, deproteinization etc. were the main steps followed by filtration and drying. The chitin and chitosan extracted as described by Gadgey and Dey 2017[21] with some modifications.

\subsection{Preparation of Chitosan Films}

Chitosan films were prepared by solution casting method. The prepared chitosan was used for film preparation. Acetic acid was used as a solvent and glycerol was used as a plasticizer. The films were prepared by the solution casting as described by Han et al. [22] with some modifications. The extracted chitosan from Narmada riverside crab shells were used to prepare the chitosan film. In a $250 \mathrm{ml}$ beaker $100 \mathrm{ml}$ demineralized water was used to dissolve $2 \mathrm{gm}$ chitosan with $2 \mathrm{ml}$ acetic acid. The solution was stirred overnight with magnetic stirrer on hot plate at $40^{\circ} \mathrm{C}$ temperature. After complete dissolution of chitosan, glycerol was added as a plasticizer. Four moulds were prepared with 0\%, 30\%, 60\% and 90\% glycerol (w/w of chitosan). The samples are coded as CS-00, CS-30,CS-60 and CS-90 respectively. The solution was filtered through coarse sintered glass filter to remove un dissolved impurities. The solution was poured onto glass moulds. The films were dried for four days at ambient temperature. The films were peeled off and conditioned for testing.

\subsection{Specimen Preparation}

The peeled off films were cut into pieces to prepare specimens. The specimens were stored separately according to their compositions.

\subsection{Film Thickness Measurement}

Film thickness was measured using a Dial Micrometer Mitutoyo, SN. 7327P. The least count was one micron and range 0 to 1000 micron. Ten measurements were taken at random positions around the film samples and the mean values were calculated.

\subsection{Tensile Testing of Chitosan Based Films}

Mechanical properties were determined using a tensile test with grip separation of $50 \mathrm{~mm}$ and speed rate of $0.9 \mathrm{~mm} / \mathrm{s}$, according to the ASTM D882 standard method. The samples were cut into strips $(20 \mathrm{~mm} \times 100 \mathrm{~mm})$. These tests were carried out using a Tensile Testing Machine, Model Dutt 105, Ahemdabad(India).

\section{RESULTS AND DISSCUSSIONS}

Narmada riverside crab shells processed to prepare chitosan based films. The films were tested for tensile strength and percentage elongation. Table 1 shows Tensile Strength and Elongation at Break of Chitosan based films incorporated with different Film Thickness. 
Investigation of Mechanical Properties of Chitosan Based Films Prepared from Narmada Riverside Crab Shells

Table 1 Tensile Strength and Elongation at Break of Chitosan based films incorporated with different Film Thickness

\begin{tabular}{|c|c|c|c|c|}
\hline S.NO. & Sample & $\begin{array}{c}\text { Film Thickness } \\
\text { mm }\end{array}$ & $\begin{array}{c}\text { Elongation at Break } \\
\text { \% }\end{array}$ & $\begin{array}{c}\text { Tensile Strength } \\
\text { MPa }\end{array}$ \\
\hline 1. & CS-G00 & 0.110 & 13.6 & 122.62 \\
\hline 2. & CS-G30 & 0.126 & 30.8 & 85.03 \\
\hline 3. & CS-G60 & 0.268 & 39.6 & 40.75 \\
\hline 4. & CS-G90 & 0.324 & 45.6 & 32.68 \\
\hline
\end{tabular}

\subsection{Film Thickness Analysis}

The thickness of the Chitosan based films ranged between 0.110 and $0.324 \mathrm{~mm}$, and the values were significantly influenced by the loading concentration of plasticizer. The observations are in close agreement with Ahemed et al. 2017 [23] and Shankar et al. 2016[24]. Bhuwaneshwar et al. 2011[25] prepared chitosan films with different percentage of chitosan and acetic acid. The film with $2 \mathrm{~g}$ chitosan and $2 \%$ acetic acid achieved $0.170 \mathrm{~mm}$. The film thickness of pure chitosan film (CS-G00) is $0.110 \mathrm{~mm}$. Maximum film thickness 0.324 is observed at $90 \%$ glycerol added chitosan film. The pure chitosan film has minimum film thickness. The film thickness increases with increase in glycerol percentage. The variation of film thickness with glycerol is shown in Figure 1. There is very small increase in film thickness by adding $30 \%$ glycerol in chitosan. The film thickness significantly increases from $30 \%$ to $60 \%$ region. Again small change in thickness observed from $60 \%$ to $90 \%$ region. Thickness is very important parameter in many applications of chitosan films.

\subsection{Percentage Elongation Analysis}

Percentage Elongation at Break of chitosan based films were measured using Tensile Testing Machine with gauge length $50 \mathrm{~mm}$. The change in length recorded and Percentage Elongation at Break calculated. It is clear from the results that the EAB increases as the glycerol percentage increased. The maximum value of EAB is $45.6 \%$ whereas minimum value is 13.6 $\%$. Between CS-G00 and CS-G30 significant increase in EAB is observed. Between CS-G30 and CS-G90 constant change in EAB is observed. Figure 2 represents the Elongation at Break of Chitosan based films incorporated with different Film Thickness. Both EAB and FT increases with increase in glycerol content. Delavar \& Shojaei 2017[26] reported pure chitosan film EAB 40\%. The maximum EAB was reported by Ahmed et al. 2017[23], 72.70\% which is more than present study but at this EAB value the TS was only $6.99 \mathrm{MPa}$ whereas in the present study the TS is $122.62 \mathrm{MPa}$. Bhuvaneshwari et al 2011[25] achieved EAB 64\% at TS 44.12 MPa. The minimum EAB 2.25\% is reported by Liu et al. 2017[27] at TS 51.04 $\mathrm{MPa}$.

\subsection{Tensile Strength Analysis}

The strength of pure chitosan films and Glycerol blended films was measured on tensile testing machine. Tensile Strength and Elongation at Break of Chitosan based films incorporated with different Film Thickness is shown in Table 2. Maximum TS was recorded for pure chitosan films with TS value $122.62 \mathrm{MPa}$ at EAB $13.6 \%$ and FT $0.110 \mathrm{~mm}$. Between CS-G00 and CS-G30 significant reduction in TS is recorded. Between CS-G30 and CS-G60 nominal change in TS is observed whereas between CS-G60 and CS-G90 small reduction in TS is observed. The TS continuously decreases with increase in glycerol. The present study achieved TS $122.63 \mathrm{MPa}$ at EAB 13.6\%.. The value of Tensile Strength depends on the chitosan quality. The degree of deacetylation of chitosan also affects the value of Tensile Strength of the film. In the present study Narmada Riverside Crab shells are used to prepare 
the chitosan. The prepared chitosan is represented quality results. Khan et al 2000[28] achieved TS $67.11 \mathrm{MPa}$ at EAB 21\%.The previous research results reported TS value ranged $6.99 \mathrm{MPa}$ to $98.26 \mathrm{MPa}$. Hence the present study achieved good results. Fundo et al.201 [29] worked on chitosan- glycerol films. They reported TS $0.281 \mathrm{MPa}$, EAB $32.67 \%$ incorporated with $90 \%$ glycerol films. Figure 1, $2 \& 3$ represents the FT, EAB and TS analysis.

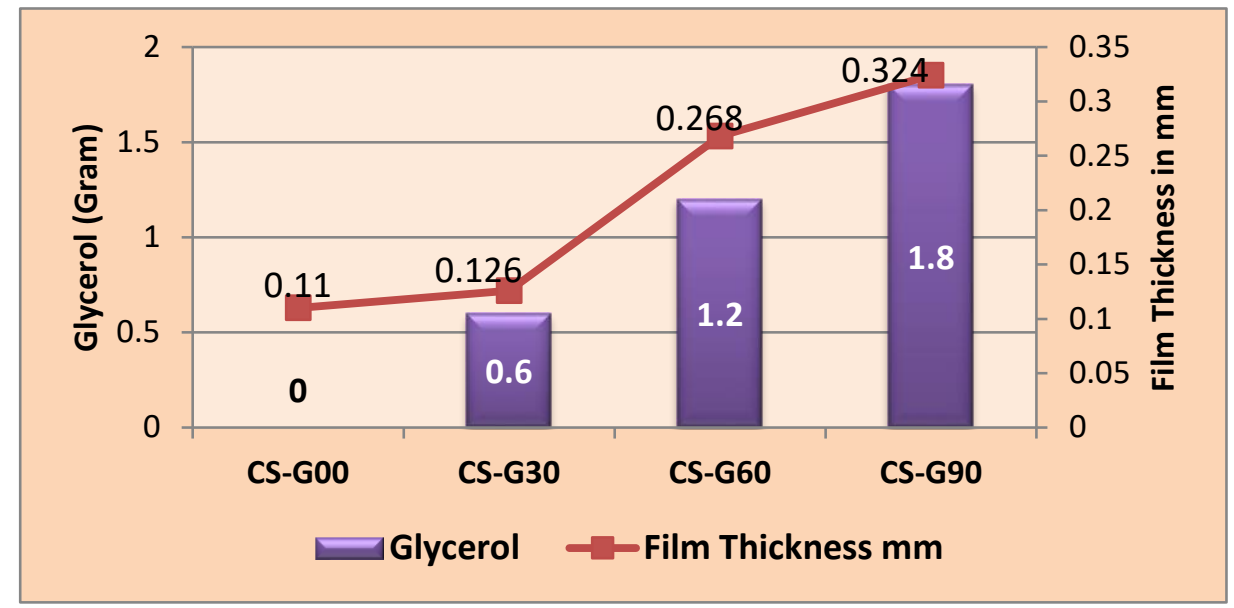

Figure 1 Film Thickness of Chitosan based films incorporated with different percentage of Glycerol

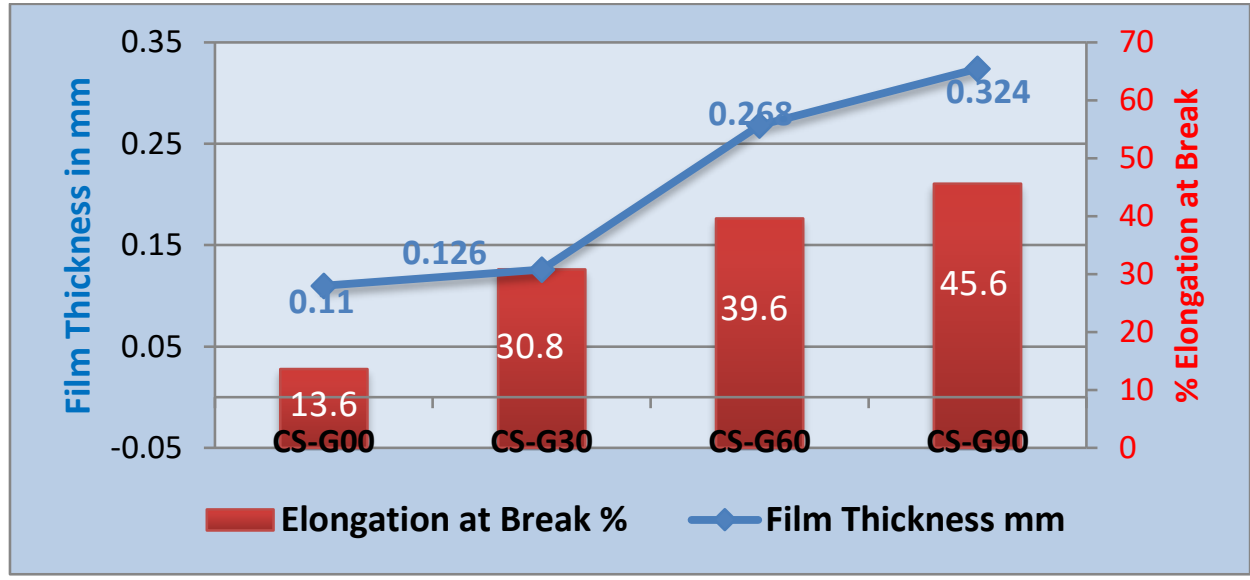

Figure 2 Elongation at Break of Chitosan based films incorporated with different Film Thickness.

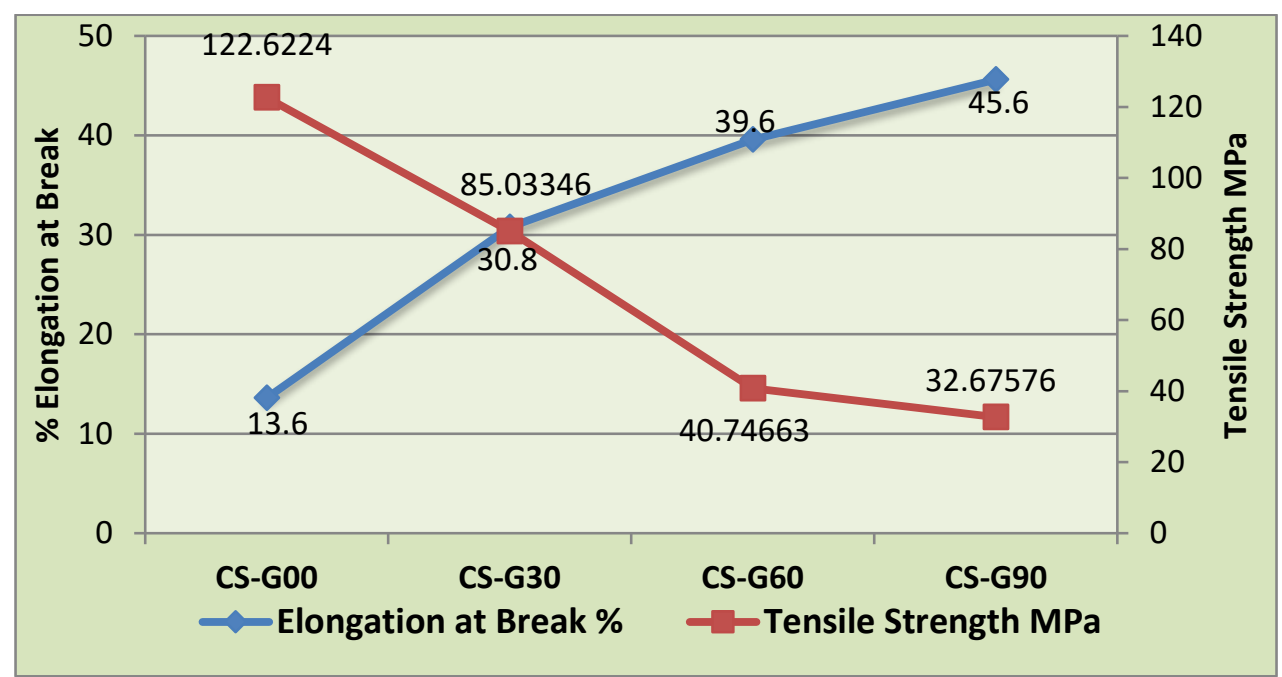

Figure 3 Tensile Strength and Elongation at Break of Chitosan based films incorporated with different percentage of Glycerol 
The mechanical characterization of chitosan based films has been done by many researchers[31]. The pure chitosan films have been characterized. Table 2 represents the various Thickness, TS, and EAB values of pure chitosan films reported earlier.

Table 2 FT, TS, and EAB values of pure chitosan films reported earlier.

\begin{tabular}{|c|l|c|c|c|c|}
\hline S.NO. & \multicolumn{1}{|c|}{ Reference } & Code & $\begin{array}{c}\text { FT } \\
\text { mm }\end{array}$ & $\begin{array}{c}\text { TS } \\
\text { MPa }\end{array}$ & $\begin{array}{c}\text { EAB } \\
\mathbf{\%}\end{array}$ \\
\hline 1. & Ahmed et al. 2017[23] & AH17 & 0.172 & 6.99 & 72.70 \\
\hline 2. & Bhuvaneshwari et al. 2011[25] & BH11 & 0.170 & 44.12 & 64.00 \\
\hline 3. & Bujang et al. 2013[32] & BU13 & 0.175 & 26.12 & 25.00 \\
\hline 4. & Chen et al. 2016[30] & CH16 & 0.026 & 98.26 & 04.16 \\
\hline 5. & Liu et al. 2017[27] & LI17 & 0.031 & 51.04 & 02.25 \\
\hline 6. & Present Work & CS-G00 & $\mathbf{0 . 1 1 0}$ & $\mathbf{1 2 2 . 6 2}$ & $\mathbf{1 3 . 6}$ \\
\hline
\end{tabular}

The FT of various previous results for pure chitosan films ranged $0.026 \mathrm{~mm}-0.175 \mathrm{~mm}$. The present work FT is 0.110. The film thickness of pure chitosan is depends on the preparation of solution. The chitosan should be completely dissolved in acetic acid solution. The film forming duration and drying condition also affect the FT. The EAB of previous results for pure chitosan films ranged $02.25 \%-72.70 \%$. The present work EAB is $13.6 \%$. The greater values of EAB of previous researches are associated with very small values of TS. The present EAB $13.6 \%$ is associated with TS $122.62 \mathrm{MPa}$. Hence the EAB in the present work is justified. The TS of previous results for pure chitosan films ranged $6.99 \mathrm{MPa}-98.26 \mathrm{MPa}$ Chen et al. 2016[30] achieved TS $98.26 \mathrm{MPa}$ which is good result but EAB is very low (04.16\%). Liu et al. 2017[27] also achieved TS 51.04 MPa but again the EAB is extremely low (02.25\%). Bujang et al. 2013[32] achieved TS 26.12 MPa associated with EAB 25.00\% and FT 0.175 .

\section{CONCLUSIONS}

Mechanical property is important for chitosan films because adequate mechanical strength can ensure film's integrity and protect film from minor defects. Tensile strength and elongation at break are two key indexes reflecting the mechanical property of film. Tensile strength is the maximum strength for a film withstanding against applied tensile stress, and elongation at break represents the ability of a film to stretch. The investigation of the mechanical properties of chitosan films are required to understand the mechanical behavior of the chitin prepared from Narmada Riverside Crab Shells. Tensile strength and Percentage Elongation at Break of the films determine their performance and integrity during storage, utilization and handling. Samples were tested for tensile strength and Percentage Elongation at Break. There is a optimum point with TS $85 \mathrm{MPa}$ and EAB 30.8\%.This optimum value is represented on CSG30 film. . The present work TS is $122.62 \mathrm{MPa}$ that suggests the researchers to use the Narmada Riverside Crab Shells for the chitosan production.

\section{ACKNOWLEDGEMENTS}

The authors would like to thank to Prof. (Dr.) M. K. Gupta, Dean, Institute of Pharmacy, Oriental University Indore, for providing necessary facilities for material processing and film synthesis. We would also thank to Choksi Laboratories Pvt. Ltd., Indore(MP), India for providing the facilities for material testing. 


\section{REFERENCES}

[1] Bhatnagar, T., Pawar, S. and Faisal. Green Technologies, International Advanced Research Journal in Science, Engineering and Technology, 2(1), 2015, pp 326-329.

[2] Vartiainen, J., M Vähä-Nissi, and Harlin, A. Biopolymer Films and Coatings in Packaging Applications-A Review of Recent Developments, Materials Sciences and Applications,5, 2014, pp 708-718

[3] Fernando, L. A. T., Pobletea, A. M. R., Ongkikoa, S G M. and Diaza, L. J. L. Chitin Extraction and Synthesis of Chitin-Based Polymer Films from Philippine Blue Swimming Crab (Portunus pelagicus) Shells, Procedia Chemistry 19, 2016,pp 462 - 468.

[4] Gadgey, K. K. and Bahekar, A. Investigation on Uses of Crab Based Chitin and Its Derivatives. International Journal of Mechanical Engineering and Technology, 8(3), 2017, pp 456-466.

[5] Jensenm \& Weis-Foght, Biology and physics of locust flight-V. Strength and elasticity of locust cuticle. Phil. Trans. R. Sot., B245, 1962, pp137-169.

[6] Hepburn, H. R. \& Ball, A. On the structure and mechanical properties of beetle shells. J. mat. Sci. 8, 1973, pp 618-623.

[7] Hepburn, H. R. \& Joffe, I. Hardening of locust sclerites. J. Insect Physiol. 20, 1974a, pp 631-635.

[8] Hepburn, H. R. \& Joffe, I. Locust solid cuticle-a time sequence of mechanical properties. J. Insect Physiol. 20, 1974b, pp 497-506.

[9] Gadgey, K. K. and Bahekar, A. Investigation of Mechanical Properties of Crab Shell: A Review, International Journal of Latest Trends in Engineering and Technology, 8(1), 2017, pp 268-281.

[10] Joffe, I. \& Hepburn, H. R. A simple low-cost tensometer for bio-materials testing. Experientia. 30, 1974, pp 113-14.

[11] [11] Neville, A.C. Biology of the arthropod cuticle. New York: Springer- Verlag; 1975.

[12] Vincent, J.F.V. Structural biomaterials. Princeton, NJ: Princeton University Press; 1991.

[13] Vincent, J.F.V. Arthropod cuticle: a natural composite shell system. Composites A. 33, 2002, pp1311-5.

[14] Vincent, J.F.V.and Wegst, U.G.K. Design and mechanical properties of insect cuticle. Arthropod Struct. 33, 2004, pp 187-99.

[15] Sanchez, C. H. Arribart, M.M. Giraud-Guille. Biomimetism and bioinspiration as tools for the design of innovative materials and systems. Nat Mat.4, 2005.pp277-88.

[16] Muzzarelli, R.A.A. Some modified chitosan and their niche applications, In Chitin Handbook, by Muzzarelli R.A.A., Peter M.G. (ed). European Chitin Society, Italy, 1997, pp 47-52.

[17] Abdou, E.S., Nagy, K.S.A. and Elsabee, M.Z. Extraction and characterization of chitin and chitosan from local sources, Bioresources Technology. 99, 2008, pp1359-1367.

[18] Nessa, F., Shah, M. M., Asaduzzaman, M., Roy , S. K., Hossain , M. M. and Jahan, M. S. A process for the preparation of chitin and chitosan from prawn shell waste, Bangladesh J. Sci. Ind. Res.45(4),2010,pp 323-330.

[19] Inmaculada, A., Marian,M., Ruth, H., Inés,P., Beatriz ,M., Niuris ,A., Gemma ,G. and Ángeles ,H. Functional characterization of chitin and chitosan, Current Chemical Biology, 3,2009,pp 203-230. 
[20] Gadgey, K.K. and Bahekar, A. Studies on Extraction Methods of Chitin from Crab Shell and Investigation of Its Mechanical Properties. International Journal of Mechanical Engineering and Technology, 8(2), 2017, pp 220-231.

[21] Gadgey, K.K. and Dey, S. Development of Chitin and Chitosan from Narmada Riverside Crab Shells, International Journal of Mechanical Engineering and Technology, 8(7), 2017,pp 298-307.

[22] Han, D., Yan, L., Chen, W. and Li, W. Preparation of chitosan/graphene oxide composite film with enhanced mechanical strength in the wet state. Carbohydrate Polymers. 83, 2011, pp 653-658.

[23] Ahmed, J., Mulla, M., Arfat, I.A., and Thai, L.A. Mechanical, thermal, structural and barrier properties of crab shell chitosan/graphene oxide composite films. Food Hydrocolloids, 71, 2017, pp 141-148.

[24] Shankar, S., Jaiswal, L., Selvakannan, P.R., Ham, K. S. \& J W Rhim, Gelatin based dissolvable antibacterial films reinforced with metallic nanoparticles. RSC Advances, 6, 2016, pp 67340-67352.

[25] Bhuvaneshwari, S., Sruthi, D., Sivasubramanian, V., Kalyani, N. and Sugunabai, J. Development and characterization of chitosan film, International Journal of Engineering Research and Applications, 1( 2),2011,pp292-299.

[26] Delavar, Z. and Shojaei, A. Enhanced mechanical properties of chitosan/nanodiamond composites by improving interphase using thermal oxidation of nanodiamond, Carbohydrate Polymers, 167,2017,pp 219-228.

[27] Liu, J., Liu, S., Chen, Y., Zhang, L., Kan, J. and Jin, C. Physical, mechanical and antioxidant properties of chitosan films grafted with different hydroxybenzoic acids, Food Hydrocolloids, 71(2017)176-186.

[28] Khan, T.A., Peh, K.K. and Ch'ng, H.S. Mechanical, bioadhessive strength and biological evaluations of chitosan films for wound dressing, J Pharm Pharmaceut, Sci,3(3),2000,pp303-311.

[29] Fundo, J. F., Quintasa, M. A. C., Cristina, L. M. and Silva, D. Influence of film forming solutions on properties of chitosan/glycerol films, 11th International Congress on Engineering and Food - Athens, Greece, 2011,pp 963-964.

[30] Chen, H., Hu, X., Chen, E., Wu, S., McClements, D.J., Liu, S., Li, B. and Li, Y. Preparation, characterization, and properties of chitosan films with cinnamaldehyde nanoemulsions, Food Hydrocolloids , 61,2016,pp662-671.

[31] Gadgey, K. K. and Sharma G. S. Investigation of Mechanical Properties of Chitosan Based Films: A Review. International Journal of Advanced Research in Engineering and Technology, 8(6), 2017, pp 93-102.

[32] Bujang, A., Adila, S.N. and Suyatma, N.E. Physical Properties of Chitosan Films as Affected by Concentration of Lactic Acid and Glycerol, 2013 4th International Conference on Biology, Environment and Chemistry IPCBEE , 58,2013,pp27-31. 